\title{
ENTRE A TÉCNICA E A TÉCHNE: POSSIBILIDADES DE ATUAC̣ÃO DO PSICÓLOGO NAS ORGANIZAÇÕES
}

\author{
Between the technique and the téchne: working possibilities of the psychologist in organizations
}

Entre la técnica y la téchne: posibilidades de actuación del psicólogo en las organizaciones

Cynara Carvalho de Abreu SyMONe FERNANDES DE MELO

\begin{abstract}
Resumo: O objetivo desse artigo é instigar a reflexão, com base no pensamento de Martin Heidegger sobre a questão da técnica, mais especificamente, acerca do espaço que comumente psicólogos têm ocupado nas organizações de trabalho, estas por sua vez inseridas em um mundo técnico pós-moderno. Psicólogos, entre outros profissionais, têm buscado conhecimento e preparo técnico específico, principalmente após a graduação, para assumirem cargos em áreas de gestão de pessoas nas organizações. Contudo, não tem sido raro ouvir profissionais de psicologia atuantes em contextos organizacionais relatarem que não se sentem mais psicólogos, que sequer recordam que o são, visto que as atividades cotidianas lhes requerem conhecimentos e habilidades que muito pouco estão associadas com a formação que escolheram. A partir da reflexão ora proposta, busca-se percorrer um caminho no qual se vislumbre possibilidades do psicólogo repensar sua prática profissional de modo a privilegiar a téchne sem precisar abrir mão da técnica e, assim, criar com esta última uma relação serenamente livre.
\end{abstract}

Palavras-chave: Psicologia do Trabalho; Téchne; Fenomenologia heideggeriana.

\begin{abstract}
The aim of this article is to instigate reflection, based on the thought of Martin Heidegger concerning the issue of technique, more specifically about the space that psychologists have commonly occupied in the work organizations, which, in turn, are inserted in a postmodern world. Psychologists, among other professionals, have sought knowledge and specific technical preparation, especially after graduation, to take up positions in areas of personnel management in organizations. However, it has not been uncommon to hear psychologists working in organizational contexts reporting that they do not longer feel themselves like psychologists, who do not even remember that they exercise their profession, because the daily activities require knowledge and skills that are very little associated with the training area they have chosen. From the reflection proposed here, we seek to follow a path in which we can glimpse the possibilities of psychologists to rethink their professional practice in such a way as to privilege the téchne without giving up the technique, and thus establish a serenely free relationship with the latter.
\end{abstract}

Keywords: Psychology at Work; Téchne; Heideggerian phenomenology.

Resumen: El objetivo de este artículo es instigar la reflexión, basándose en el pensamiento de Martin Heidegger sobre la cuestión de la técnica, más específicamente sobre el espacio que, comúnmente, psicólogos han ocupado en las organizaciones de trabajo, que a su vez forman parte del mundo técnico posmoderno. Psicólogos, entre otros profesionales, han buscado el conocimiento y la preparación técnica específica, sobre todo después de la graduación, para asumir posiciones en las áreas de gestión de personas en las organizaciones. Sin embargo, no ha sido raro escuchar a profesionales de la psicología que trabajan en contextos organizacionales reportar que no más se sienten como psicólogos, que ni siquiera recuerdan que ejercen su profesión, puesto que las actividades diarias requieren conocimientos y habilidades que muy poco se asocian con la formación que han elegido. A partir de esta reflexión, se busca seguir un camino en el que el psicólogo pueda vislumbrar posibilidades para repensar su práctica profesional de manera que se prime la téchne sin tener que renunciar a la técnica, y así crear con esta última una relación tranquilamente libre.

Palabras clave: Psicología del Trabajo; Téchne; Fenomenología heideggeriana.

\section{Introdução}

O desenvolvimento da Psicologia como ciência e profissão tem sido marcado por um processo histórico que possibilitou a construção de diferentes configurações do seu objeto. Uma dessas configurações deu-se quando a Psicologia passou a se "apropriar" do constructo trabalho, a partir de suas lentes teóricas e pragmáticas, atribuindo-lhe novos significados e fazendo dele uma "categoria chave" (Bendassolli, 2011, p.75). Na sequência, a preocupação com as organizações, sua estrutura, seu funcionamento e seus processos, bem como com os modelos vigentes de gestão, culminou em uma rede de multideterminações que imbricadas passou a ter, pelo menos em princípio, como interesse nor- teadora ação humana inscrita no interior do trabalho e das organizações (Zanelli, Bastos \& Rodrigues, 2014). Assim, mundo afora, e no Brasil - mais especificamente nas primeiras duas décadas do séc. XX, a área da Psicologia que se dedica às questões do fazer humano no trabalho e nas organizações vem passando por significativas, às vezes polêmicas, mas sempre nobres, transformações (Borges, 2010). É em função desse movimento de cunho edificante que essa área tem cada vez mais se consolidado como um vasto e reconhecido campo científico e de atuação profissional do psicólogo.

Reconhecido tornou-se esse campo de atuação para o psicólogo, isso é inegável. Contudo, parece carregar em si algo proporcionalmente confuso e permeado de conflitos e tensões. Ainda que essa 
área demande interdisciplinaridade com outros campos de saber como, por exemplo, a Sociologia, a Antropologia, a Economia, a Administração, ou seja, requeira necessariamente a “... integração de uma ou mais disciplinas em uma nova abordagem, com a consequente construção de seus próprios objetos, conceitos, premissas e paradigmas" (Santos, 2007, p. 54), a Psicologia, a exemplo da Psicologia do Trabalho e das Organizações, tem frequentemente "negociado" e não dialogado suas fronteiras com outros campos profissionais, como parece que tem feito, já há algum tempo, com a Administração.

Apresentando uma pesquisa realizada em 2008 pela Associação Brasileira de Recursos Humanos - ABRH, Malvezzi, Souza e Zanelli (2010) chamam atenção para o fato dos psicólogos e os administradores aparecerem como profissionais tecnicamente equiparados para assumirem cargos em áreas de gestão de pessoas nas organizações. "Em busca de habilidades para atingir a condição de especialização flexível e uma bagagem carregada de “competências portáteis", ou seja, que podem ser utilizadas em várias situações de atuação profissional, os profissionais têm participado de vários cursos, obscurecendo as fronteiras entre as profissões" (Malvezzi, et al., p. 86) e deixando-lhes escapar das mãos a chance de se aprofundar naquilo que lhes é próprio por formação. Desta forma, no mais das vezes, ela, a Psicologia, tem se deixado esmaecer no meio de tantas explicações sobre a relação do comportamento humano com o trabalho e os contextos em que ele se realiza. Algo tem acontecido com os psicólogos ao efetivamente chegarem nesse lugar e ao assumirem esse espaço, por vezes tão almejado, nos contextos das organizações de trabalho. Em alguma medida, não se sabe precisar o porquê, alguns "acabam aprendendo a reproduzir discursos e ficam incapacitados para agir diante de problemas concretos e de indivíduos e grupos singulares" (Zanelli et al., 2014, p. 564).

Não tem sido raro ouvir profissionais de psicologia atuantes em contextos organizacionais relatarem que não se sentem mais psicólogos, que sequer se lembram que o são, que, a bem da verdade, as atividades que comumente desenvolvem lhes requerem conhecimentos e habilidades que muito pouco ou quase nada têm a ver com a formação que receberam no curso de graduação em Psicologia. O pior cenário se instala. Ora, sendo a atuação na área do trabalho e das organizações essencialmente interdisciplinar, ou seja, implicada em um diálogo construído entre disciplinas diferentes (Santos, 2007), e tendo o psicólogo, em alguma medida, optado por se calar dentro desse espaço dialógico, mesmo não sendo sua intenção, passa a contribuir lentamente para a perda de sua identidade profissional, bem como para a destituição das características que o distinguem dos outros profissionais que atuam neste tão vasto e reconhecido campo de atuação profissional. Zanelli et al. (2014, p. 564) chamam atenção, inclusive, para o fato de que em alguns casos esteja se perdendo de vista ou até se abandonando "a perspectiva do fenômeno psicológico ou o âmbito individual que classicamente lhe foi confiado nessa divisão do trabalho”.

Situações assim são comuns em contextos de organizações de médio e grande portes, nas quais dos psicólogos são exigidas competências técnicas, pessoais, interpessoais e políticas para desenvolver atividades que perpassam a psicologia do trabalho, que priorizam ações voltadas para a promoção do bem-estar no trabalho e saúde do trabalhador, por exemplo; e a psicologia organizacional que tem a atenção voltada para os processos psicossociais no nível do indivíduo, dos grupos e das organizações e, também pela gestão de pessoas que tem foco em atividades voltadas para a implantação e manutenção de políticas e práticas de captação, integração, avaliação, desenvolvimento e retenção de pessoas (Zanelli et al., 2014).

Se esse panorama já tem sido suficiente para gerar inquietações acerca do lugar que o psicólogo tem ocupado e conseguido sustentar nas organizações de médio e grande portes, sejam elas de iniciativa privada ou pública, é preciso destacar que no Brasil o número de psicólogos que se inserem em organizações com essas características é pequeno quando comparado ao quantitativo de profissionais que se formam anualmente. Dados da pesquisa realizada em 2006 pelo Conselho Federal de Psicologia - CFP, Quem é o psicólogo brasileiro? apresentada por Gondim, Bastos e Peixoto (2014, p. 180), apontam que já, há dez anos, havia "menos psicólogos dedicando-se exclusivamente à área organizacional e do trabalho do que no final da década de 1980”. A terceirização, a instabilidade dos empregos e as novas configurações de vínculos trabalhistas podem ser consideradas causas para esse cenário. Não obstante, a grande porta de entrada para a área, principalmente para os recém-formados, tem sido o exercício de atividades de consultoria, seja através de atividades profissionais autônomas ou através da constituição de micro ou pequenas empresas para esse fim. As primeiras oportunidades de atuação profissional para o psicólogo, ressaltam Malvezzi et al. (2010), são oriundas de pequenas ou médias empresas, em sua maioria da iniciativa privada, que têm como objetivo principal prestar serviços de seleção de pessoal, atividade na qual ainda há grande destaque para a psicometria como prática prevalente, seguida de diagnóstico organizacional, consultoria organizacional (grande parte voltada para desenvolvimento de ações de capacitação, palestras, workshops, etc.) ou para estruturar ou dar continuidade ao trabalho de implantação de setor/ departamento de Recursos Humanos ou Gestão de Pessoas. Gondim et al. (2010) têm questionado se esse movimento representa um sinal de consolidação ou de enfraquecimento da área.

O que de fato inquieta é que, diante de um campo reconhecidamente consolidado, se por um lado é sabido que há muito a se fazer, por outro, algo parece estar nos escapando. Enquanto se esforça em busca de conhecimentos interdisciplinares, para responder às solicitações prementes aos contextos de trabalho e das organizações, o psicólogo tem se deparado com situações por ele não previstas, como por exemplo com pessoas em situação de 
sofrimento psicológico e precisando de tipos mais específicos de ajuda. Falta de sentido no trabalho ou na vida, ideias de morte, de estar vivendo crises, medos e dilemas são alguns dos conteúdos dos relatos dos que o procuram. Nem sempre esse psicólogo tem clareza sobre como acolher essas demandas, segurança sobre como com elas trabalhar e, sobretudo, comumente tem se sentido confuso sobre se é possível atender essas demandas individuais, conciliando-as com todas as outras organizacionais para as quais estava buscando desenvolver conhecimentos, habilidades e atitudes. Uma onda de novas solicitações incide sobre esse profissional que nem lembrava mais que era psicólogo, nem sabe se pode parar e oferecer uma escuta a quem lhe pede, que se sente afetado pela história de vida ou pelo sofrimento pontual de um e de outro funcionário, que se esqueceu de ser psicólogo e foi ser do trabalho e das organizações. Isso tem sido uma questão que tem interpelado suas práticas, seus saberes, seu lugar, sua profissão.

O objetivo deste artigo é, portanto, enfrentar tais indagações, sem esquivas, optando, para tal, por um caminho original, e mesmo ousado, ao buscar no pensamento do filósofo Martin Heidegger, os recursos para compreensão das questões que se colocam. A partir da filosofia da existência faremos uso de novas lentes para, com os mesmos olhos, tentarmos enxergar o que poderiam vir a ser outras possibilidades para o psicólogo nos contextos de trabalho e das organizações, no que se refere a sua atuação profissional. Para tanto, faremos articulações com base nas ideias heideggerianas sobre a técnica moderna, que tem duas fundamentais perspectivas: uma, puramente tecnológica, na qual está totalmente imersa na sociedade contemporânea, inclusive, no mundo do trabalho e das organizações, que prioriza o pensamento que calcula, que planeja, que busca o controle, o domínio das coisas da natureza e, claro, das questões humanas. Nesta perspectiva, há sempre um desafio à natureza e ao homem. E a outra, não necessariamente oposta à primeira, mas de sentido mais originário (Heidegger, 1951/2012) chamada de téchne, na qual "o comportamento frente à natureza é um deixar-acontecer, sem desafiar e aceitando os limites do acontecer" (Feijoo, 2004, p. 88). Outra ideia postulada pelo filósofo e que nos acompanhará será a da serenidade, que diz de uma atitude do sim e do não simultâneos em relação ao mundo técnico moderno (Heidegger, 1959/2001).

Com essas ideias seguiremos o percurso que ora se inicia. Primeiro, será contextualizado que campo de atuação é esse, o da Psicologia voltada para os fenômenos que ocorrem atrelados ao trabalho e às organizações e em que mundo ele se ancora. Na sequência, será tecida uma análise do espaço que o psicólogo tem ocupado nas organizações, mas uma análise no sentido apresentado por Heidegger (1947/2009, p. 152) que significa o soltar, "desfazer de uma trama em seus componentes" para que se consiga enxergar exatamente o que se mostra (P. Evangelista, comunicação pessoal, 11 de Agosto de 2016) e na tentativa de uma compreensão críti- ca sobre como têm se dado as relações homem-trabalho-organizações na era da técnica moderna, as suas dimensões, suas peculiaridades e os sentidos a elas atribuídos. À guisa de conclusão do artigo e de abertura de agenda para muitas outras discussões acerca dessa temática, procuraremos tecer considerações sobre possibilidades de atuação profissional que possam guiar o psicólogo pelas veredas da serenidade (Heidegger, 1959/2001) no campo do trabalho e das organizações. O propósito maior não é obter respostas, mas, pelo menos, fazer surgir novas questões. Isso sim, terá sido ao final deste artigo, um bom começo para um longo caminho a ser percorrido.

\section{Havia uma Psicologia em meio ao Trabalho e às Organizações...}

Ao longo da história, notadamente a partir do surgimento da sociedade industrial, a Psicologia passou a conferir um olhar mais próprio tanto ao trabalho como às organizações que, não tardou, tornaram-se, para essa jovem Ciência, campos de pesquisa, de produção de conhecimento e de atuação profissional (Borges, 2010).

Mundo afora, desde o advento da máquina a vapor, a partir da segunda metade do séc. XVIII., tentar entender como se dá a relação entre os modos de ser dos indivíduos e seus modos de produzir, passou a ser uma busca constante de vários profissionais atuantes em contextos de trabalho, como por exemplo o psicólogo, visto que esse entendimento tem sido considerado um dos fatores determinantes para a manutenção de um suposto "equilíbrio econômico, da saúde e da felicidade humanas" (Malvezzi, 2014. p. ix). A necessidade de compreensão acerca do desempenho humano, fluxos de produção, funcionamento dos grupos, vínculos do indivíduo com o trabalho e com as organizações, entre outros processos ocorridos nos ambientes organizacionais, parece ter criado as condições para que a Psicologia adentrasse os contextos de trabalho, uma vez que já vinha, há algum tempo, apropriando-se do constructo trabalho, percurso esse diligentemente explorado por Bendassolli em seu livro Psicologia e Trabalho: apropriações e significados, publicado em 2009.

No Brasil, a Psicologia se insere nos contextos organizacionais nas primeiras décadas do séc. XX e, desde então, o crescimento e a consolidação da área têm sido marcados pelo trabalho contínuo, determinado e responsável de um coletivo de profissionais comprometidos tanto com a atuação profissional como com pesquisas e publicações científicas de qualidade sobre esse campo (Malvezzi, 2014). Na tentativa de se propor a compreender a relação homem-trabalho, a Psicologia assume um papel de parceria importante com a gestão organizacional, passando a assumir no desenvolvimento dessa área três momentos ou três "psicologias" do trabalho (Bendassolli, 2011), que embora se sucedam, representam efetivamente a ampliação de foco que o seguinte incorpora em relação ao anterior e não a sua extinção, a saber: 
O primeiro momento, conhecido como o da Psicologia Industrial, caracterizou-se pela propagação das atividades do psicólogo no país, sobretudo em função da larga aplicação de testes psicológicos a partir de 1930 (Zanelli et al., 2014). A inserção dos profissionais de psicologia nas empresas objetivava prioritariamente o aumento da produtividade e a seleção de pessoas. Logo depois, com a intensificação das indústrias, surge o segundo momento da Psicologia, a chamada Psicologia Organizacional. Nesse contexto, o psicólogo era demandado a atuar com foco no trabalho em grupos e igualmente com vistas ao aumento da produtividade. As atividades de treinamento e desenvolvimento, bem como de avaliação de desempenho eram priorizadas entre suas ações. Para tanto, a área de gestão de recursos humanos fora impulsionada corporativamente. Autores como Spink (1996) e Zanelli et al. (2014) chamam a atenção para a atuação irrefletida do psicólogo dentro desse contexto e destacam as críticas a ele feitas visto que, no mais das vezes, esse profissional atuou de forma a desconsiderar as demandas sociais e a reproduzir práticas e discursos que considerava somente as necessidades da organização. A partir dessa mobilização crítica acerca da atuação do psicólogo do trabalho e das organizações, emerge o terceiro momento, no qual o trabalho assume o "papel relevante para compreender não apenas o desempenho do indivíduo, das equipes e da organização, mas especialmente os problemas de saúde do trabalhador" (Zanelli et al., 2014, p. 560). Surge a então intitulada Psicologia do Trabalho. A partir desse momento a Psicologia convida o seu profissional, os seus pares e a sociedade a olhar para o trabalho não só como emprego, mas como operador de uma função psicológica para o sujeito, a considerar a existência de uma relação entre vida psíquica e trabalho (Clot, 2007; Bendassolli, 2011) que escapa ao domínio dos processos organizativos (Spink, 1996). Na vertente da Psicologia do Trabalho, outros temas se somam ao rol de possibilidades de pesquisa, produção de conhecimento e de atuação profissional do psicólogo, como por exemplo, desemprego, subemprego, condições de trabalho, riscos psicossociais, políticas públicas de geração de emprego e renda, saúde psíquica e trabalho, dentre outros.

A atuação desse psicólogo sofreu, evidentemente, influências ocorridas no mundo do trabalho ao longo do tempo. No Brasil, houve alguns momentos em que a consolidação da área esteve mais fortalecida e, em outros, bem fragilizada. A despeito das tensões internas inerentes às questões ideológicas, tecnológicas ou de ordem teórico-metodológicas, Borges (2010) lembra que sempre houve um esforço coletivo para a manutenção de uma identidade profissional do psicólogo dedicado a compreender, a intervir e a "investigaras relações dos homens e das mulheres com o seu trabalho" (Coelho-Lima, 2013. p.16) e seus contextos. Em 29 de novembro de 2009, com o intuito de defender e fundamentar a necessidade de que trabalho e organização não sejam vistos, trabalhados, estudados e compreendidos pelos psicólogos como mundos separados, a
Associação Brasileira de Psicologia Organizacional e do Trabalho - SBPOT divulgou um manifesto que valoriza a inter-relação entre a categoria trabalho e organizações e defende que a separação entre eles causaria não só uma cisão, mas uma contradição, um desserviço, um desrespeito, uma negativa à possibilidade de complementaridade. É em função dessa perspectiva que se adota para a área o nome Psicologia Organizacional e do Trabalho (POT), podendo-se ainda encontrar as variações Psicologia das Organizações e do Trabalho (PO\&T), bem como Psicologia do Trabalho e das Organizações (PT\&O), que antecede o conceito Trabalho ao de Organizações, por considerar o argumento epistemológico de que aquele é antecessor a este (Coelho-Lima, 2013) e que será a terminologia com a qual seguiremos deste ponto em diante tanto para nos referirmos à área quanto ao profissional.

\section{O Psicólogo, as Organizações e a Técnica Moderna}

Não tem jeito. Olhamos para um lado, para o outro, para frente, para trás, para dentro e para fora, inclusive para si próprio e o que vemos? Pessoas, nos mais diversos contextos e culturas, a despeito da idade, de alguma forma, vinculadas a uma ou mais organizações (Zanelli et al., 2014). E a vida em sociedade? Essa depende de forma complexa do funcionamento de um entrelaçado de organizações de vários tipos e funções que lhe disponibilizam produtos e serviços, diretos e indiretos, como por exemplo, alimentos, energia elétrica, saúde, educação, transporte, vestuário, dentre outros. Podemos afirmar, portanto, que é uma grande teia de organizações que hoje, mais do que nunca, faz a vida do homem funcionar nos moldes que conhecemos e estamos inseridos.

Por organizações, Zanelli et al. (2014. p. 550) entendem o "modo como as pessoas e os grupos se estruturam para atender a suas próprias necessidades" e destacam que o seu funcionamento depende, em grande medida, do trabalho humano. Não é difícil imaginar que quanto maior o número de organizações, maior será a quantidade de pessoas a elas vinculadas pelo trabalho e que essa relação gera, necessariamente, uma dependência mútua.

As organizações, por sua vez, protagonizam um mundo no qual se preconiza as interações mediadas por artefatos tecnológicos como um dos seus elementos organizadores centrais e na tentativa de sobrevivência no mercado corporativo mergulham em busca de modelos inovadores de gestão, experimentam novos formatos corporativos, de organização do trabalho e gerenciamento de pessoas. Incubadoras, startups, e-commerce, fusões, aquisições, just-in-time, empreendedorismo, profissionalização da gestão, são alguns dos nomes que se somam às novas realidades desses ambientes e, obviamente, do cotidiano dos que neles estão.

Com tantas transformações sociais, políticas, econômicas e tecnológicas, desde o final do séc. XVIII, passando pelo advento da internet em meados do séc. XX e mais recentemente, a partir de 
2007, com o impacto da tecnologia digital mobile no mundo dos negócios, surge também a necessidade de se inventar novas formas de experimentar o tempo e o espaço, as relações do homem com o trabalho e com os seus contextos, que agora, primam menos pela tradição, mais pela mobilidade e pela velocidade. Há sempre dúvidas se o que está se fazendo é o certo, o adequado, o melhor, o mais atual, o que é mais eficiente. Há sempre dúvidas. Persiste uma sensação angustiante de que nada basta e por mais que se faça, há a necessidade de algo novo, algo a ser construído, de preferência rápido e de muito boa qualidade.

Esse é o cenário atual e o contexto do mundo organizacional que em grande medida justifica a inserção do psicólogo como parte de uma equipe interdisciplinar. Isto porque, a participação desse profissional se mostra fundamental para que se construa não só um diálogo, mas ações que aglutinem diferentes e complementares saberes e práticas com vistas ao alcance de objetivos compartilhados diante de cenários tão desafiadores. Para tanto, dos psicólogos do trabalho e das organizações é esperado o desenvolvimento de competências que lhe permitam capacidade de leitura e atuação estratégica na organização, como por exemplo, conhecimentos sobre

...processos de trabalho, ter consciência das atribuições individuais e das unidades, bem como articular visão, missão, valores, metas e estratégias organizacionais. A partir desses saberes, são possíveis ações como aumentar a capacidade estratégica, consolidar predisposições para mudanças e fortalecer a formação de equipes de alto desempenho. (Zanelli et al. 2014, p.575)

Parece claro, simples, mas tem sido exatamente diante dessa expectativa sobre sua atuação e quando se vê imerso nesse contexto, que alguns psicólogos têm se dado conta de que algo lhes escapa às mãos. Então vem a sensação de estarem perdendo algo que um dia acreditaram possuir: certezas. Afinal, estava tudo ali, à sua frente, cientificamente estudado, previsto, planejado, sob controle, estava tudo pensado. Pensado? Ou seria calculado?

Ora, imersos em um furacão de demandas cotidianas, todos, não só o psicólogo, são levados por um movimento frenético que põe o pensamento a calcular, bem como a agir de modo a dispor de si mesmos, dos outros e da própria natureza ao seu redor como entes (Heidegger, 1947/2009) a serem explorados e dos quais se deva obter o "máximo de rendimento possível com o mínimo de gasto" (Heidegger, 1951/2012, p. 19). O grande objetivo é a produtividade, é o chegar às finalidades, ao resultado. O convite ao leitor, a partir daqui, pode parecer ousado, mas enxergar com outras lentes essa "busca por resultados organizacionais", pode nos levar a outros olhares. Sigamos.

Em "A questão da técnica”, Heidegger (1951/2012) nos faz pensar acerca da técnica moderna. A palavra técnica, que, em princípio parece ser muito familiar na linguagem do meio organizacional, pode se mostrar a partir de outra perspectiva a partir das reflexões que o filósofo apresenta. Vejamos como podemos concatená-las com a linha de raciocínio sobre o contexto de atuação no qual se encontra o psicólogo do qual estamos falando.

Ao abordar o tema técnica moderna, Heidegger chama a atenção para o fato de que no mundo em que a técnica é prevalente (a propósito, este em que vivemos e ao qual temos nos referido neste texto) o homem tende a ver a si mesmo como destinado a dominar, manipular o mundo e os outros (Silva \& Barreto, 2015). Pensar assim, coloca-nos em uma condição de crer e agir como se toda natureza existisse para ser explorada, armazenada, transformada e distribuída, inclusive o homem, que é visto como algo a ser usado, disposto, calculado, que deve ter uma utilidade, esta, por sua vez, desvelada pela técnica (Heidegger, 1951/2012; Silva \& Barreto, 2015; Silva, 2007; Critelli, 2002). A lógica da técnica moderna, como um simples meio para um fim, parte do princípio que nada deve existir sem uma finalidade (Silva \& Barreto, 2015).

Ao afirmar que "a técnica moderna é um meio para um fim” (Heidegger 1951/2012, p.12), o filósofo nos faz pensar na função instrumental ou antropológica da técnica e entender o que nos move a querer manipulá-la, da melhor maneira possível, enquanto meio ou ferramenta, para prover resultados, alcançar objetivos. Essa é uma situação que se aplica cotidianamente não só para o psicólogo do trabalho e das organizações, mas para os que atuam em outras áreas, inclusive aqueles da Psicologia Clínica, como bem aponta Dutra (2013). A busca pelo conhecimento, domínio e controle da técnica é uma tensão diuturna. Curiosamente, o que tem se mostrado cada vez mais é que quanto menos o homem domina a técnica com essa intenção, como um meio para um fim, mais ela o ameaça e mais urgente se faz o desejo, o ímpeto de dominá-la. Daí o investimento em estratégias, em planejamento, em novos processos, elaboração de cenários e o círculo vicioso se renova. Ora, o raciocínio parece óbvio: quanto mais destreza e domínio tem-se de um instrumento, de uma ferramenta, ou seja, da técnica, mais eficientemente dela se fará uso e, assim, as chances de se obter os resultados para o qual ela foi concebida é bem maior, certo? Certo, mas somente em parte, posto que isso não é tudo! Para Heidegger, "A concepção da técnica como agenciamento de meios para a consecução de fins" é correta, mas não é o verdadeiro sobre ela. Não "se trata apenas de fazer algo, a partir de alguma coisa, para um certo fim” (Silva, 2007, p. 369), visto que, ao se fazer uso da técnica, há uma produção e todo produzir gerado pela técnica é, no sentido grego, um trazer para a frente, um conduzir para diante (poiésis), um movimento de levar, de chegar diante de alguma coisa que ainda não é, de fazer emergir algo que não se mostraria senão através da técnica (Costa, 2014). E assim, é a partir do que a técnica pode desencobrir, desvelar, que reside a sua essência (Costa, 2014; Critelli; 2002; Duarte; 2010; Heidegger, 1951/2012; Silva, 2007; Silva \& Barreto, 2015;). 
Essa mesma técnica moderna, destaca Duarte (2010), não consegue manter uma harmonia com a natureza, como fazia a técnica grega. Ela é agressiva de forma contínua e sufocante, de modo que se torna "uma provocação [...], um desafio que se lhe impõe e cujos resultados trazem consigo o domínio planejado e calculado daquilo que assim se desoculta” (Duarte, 2010, p. 129). A técnica moderna é capaz de nos trazer a nítida sensação de "coisificação" dos contextos e das relações de trabalho, como se deles arrancasse, a todo e qualquer custo, as condições para sua manutenção. Na tentativa de controlar, de dominar as demandas que chegam exigindo, requerendo, mexendo, agitando o funcionamento das organizações, as ações do psicólogo (e equipe) terminam por considerar o homem um sujeito objetivado (Silva \& Barreto, 2015).

Diante do exposto, não é difícil compreender o estranhamento que sente o psicólogo, que teve a maior parte da sua formação graduada voltada para aprender a como permitir "que o homem transpareça a si mesmo ao seu modo e a partir de si mesmo" (Feijoo, 2004), ao se deparar como protagonista em um ambiente de trabalho no qual "a técnica moderna não se limita a trazer os entes à presença, mas os descobre já como matéria bruta ou recurso energético que pode ser continuamente reutilizado, transformado, economizado e manipulado em um ciclo supostamente infinito" (Duarte, 2010, p.130). Diante desse cenário, o horizonte é nebuloso e o desalento se instala, a voz se cala e, no mais das vezes, esse profissional é capturado de si mesmo, de suas ideias e de sua visão de homem e de mundo.

\section{Entre a Técnica e a Téchne: caminhando pelas veredas da Serenidade}

Há de se perguntar: o que pensar então o psicólogo acerca de sua atuação profissional diante de um horizonte organizacional marcado por tamanho determinismo tecnológico e no qual a Psicologia poderia ter um papel fundamental para atenuar suas prováveis consequências, como questiona Spink (1996)? Avançar na compreensão das ideias de Heidegger, talvez nos faça enxergar novos caminhos, que passaremos a chamar de veredas ${ }^{1}$, visto que nos conduzirá a terrenos talvez ainda não visitados, paisagens ainda não apreciadas, mas sempre nutridos por um elemento fundamental, similar à água, que aqui denominaremos de liberdade ${ }^{2}$.

A ideia de considerar o mundo técnico moderno como uma fatalidade é considerada por Heidegger como uma insensatez. Ainda que estejamos destinados a existir em um mundo assim, tecnológico, ressalta Duarte (2010), temos a condição de liberdade que coloca o homem na direção do que se

1 O termo vereda foi escolhido por ter um sentido que em muito se alinha com o propósito do pensamento de Heidegger, posto que nos remete à ideia sobre serenidade. Ao significar "caminho estreito por onde correm as águas" (Ferreira, 2005. p. 04) entende-se Vereda como significando direção, rumo, caminho que pode se mostrar ora estreito, denso, escuro, úmido, com vegetação alta, ora aberto, claro, pouco úmido, com vegetação baixa, mas sempre um caminho, uma direção, um rumo traçado pela água (leia-se: liberdade) que dependendo da medida, refresca e nutre ou inunda e afoga.

2 Liberdade, para Heidegger, é muito mais que a capacidade de um indivíduo decidir sobre isso ou aquilo. (Duarte, 2010) mostra, em uma escuta meditativa e, por isso, diante de uma relação potencialmente mais livre com a técnica moderna e tudo o que a ela se remeta. Sobre o modo de pensar nesse mundo técnico moderno (Heidegger, 1959/2001, p. 13) destaca que existem dois tipos de pensamentos: um que calcula e o da reflexão, ou seja, o que medita. Sobre o que chamou de "pensamento que medita", o filósofo aponta que é, por vezes, exigente, de grande esforço, que requer treino, que carece de cuidado e afirma que para podermos "meditar, refletir sobre o que está mais próximo, é preciso nos demorarmos junto do que está perto". Acerca do que denominou de "pensamento que calcula” (Heidegger, 1959/2001, p. 13), destaca aspectos, aparentemente óbvios, como: "o pensamento que calcula não é um pensamento que medita”; “... nunca chega a meditar”, ao passo que chama atenção para sutilezas como: "o pensamento que calcula [...] não é um pensamento que reflete sobre o sentido que reina em tudo o que existe" ou ainda, "o pensamento que calcula corre de oportunidade em oportunidade. [...] nunca para.” Por fim, o filósofo ressalta que ambos, à sua especificidade, respectivamente, são legítimos e necessários. (Heidegger, 1959/2001.)

É certo que a técnica moderna representa um perigo para o homem, visto que o captura de maneira sorrateira, quando não abrupta e violenta. Uma das principais consequências disto, consiste na "perda das capacidades genuinamente humanas, de compreender e pensar, em favor do cálculo estrito das consequências que se dá, principalmente, em função do predomínio do pensamento calculador sobre a meditação serena do sentido" (Duarte, 2010, p. 195). Contudo, diante desse iminente perigo, Heidegger (1951/2012, p. 31) alude a uma esperança ao citar o verso de Hölderlin: "Ora, onde mora o perigo é lá que também cresce o que salva”. Com isso, nos diz que é na própria técnica moderna que captura, calcula, cega, coisifica, desespera, devasta a natureza e o homem, que também mora o caminho que leva ao que dela salva, sendo "salvar" compreendido como "chegar à essência, a fim de fazer aparecer o seu próprio brilho" (Heidegger, 1951/2012, p. 31). Esse caminho se trilha a partir de uma relação mais livre com a técnica e só se realiza via pensamento meditante.

O cotidiano do psicólogo do trabalho e das organizações se destina a fazer uso da técnica em si mesmo, nos outros, com os outros, para os outros, pelos outros. Inevitável. Entretanto, o que verdadeiramente incomoda não parece ser o fato do mundo estar cada vez mais técnico. Heidegger (1959/2001, p. 21), em sua conferência intitulada Serenidade, afirma que o que realmente inquieta é o fato de não conseguirmos, de não estarmos preparados para, através do pensamento que medita, "lidarmos adequadamente com aquilo que, nesta era, está a emergir”. De que forma se cultiva o pensamento meditante $^{3}$ ? Como refletir em um mundo que nos demanda o tempo todo pensamentos calculantes? Serenidade para Heidegger (1959/2001, p. 24) é “... esta atitude

3 Pensamento meditante ou meditativo: "não calcula resultados nem pretende oferecer soluções práticas e aplicáveis para quaisquer dilemas, mas busca o ser em sua verdade" (Duarte, 2010, p. 155). 
do sim e do não simultâneos em relação ao mundo técnico" e ao chamar a atenção para a necessidade de nos pensarmos e nos reconhecermos como matéria ou recurso humano, o filósofo destaca que esse desencobrimento só é possível de acontecer a partir de uma atitude humana preparada e esperada na meditação (Duarte, 2010). Isto, porque acredita que o caminho para o que nos é mais próprio e mais próximo, tem sido comumente o caminho mais longo e por isso mais difícil de se percorrer, visto que só há uma via: a reflexão, a meditação. Heidegger lembra que o nível de dificuldade nesse pensamento reside na necessidade de que nos ocupemos com o que, em princípio, parece-nos inconciliável, ou seja, não é lógico, racional. Isso tem um custo, ou melhor, vários custos no mundo técnico moderno e obviamente, no mundo organizacional.

Nesse rumo, o pensamento heideggeriano parece sugerir que o psicólogo se demore um pouco mais nesse contexto e em suas ações para, assim, conseguir enxergar o que se desencobre para além do calculado, da finalidade alcançada, de seu fim. Demorar-se, decerto, não tem a ver com ir devagar, com não fazer investir. Mas, sobremaneira, meditar, pensar sobre o processo de pro-duzir (Heidegger, 1951/2012), pois, ao estar atento a esse desencobrimento, ele se fará, diz o filósofo, ouvinte, ator e não escravo do destino. Destino este, aqui contextualizado como as demandas do mundo organizacional (missão, visão, estratégias, finanças, produção, materiais, entre outros) e por esse profissional, muitas vezes declarado como não sendo o seu.

Heidegger (1959/2001) vem propor um caminho do meio, de forma que se possa manter uma relação com o mundo técnico moderno de forma mais simples e tranquila. Desta forma, de-morando-se, há de se enxergar melhor os entes, ou seja, as situações e as pessoas não somente do ponto de vista da técnica. O filósofo nos fala de uma atitude do sim e do não simultâneos em relação ao mundo técnico moderno e a chama de: a serenidade para com as coisas (die Gelassenheit zu den Dingen):

Podemos utilizar objetos técnicos e, no entanto, ao utilizá-los normalmente, permanecer ao mesmo tempo livres deles, de tal modo que os possamos a qualquer tempo largar. Podemos utilizar objetos técnicos tal como eles têm de ser utilizados. Mas, podemos, simultaneamente, deixar esses objetos repousar em si mesmos como algo que não interessa àquilo que temos de mais íntimo e próprio. Podemos dizer "sim" à utilização inevitável dos objetos técnicos e podemos ao mesmo tempo dizer "não", impedindo que nos absorva e, desse modo, verguem, confundam e, por fim, esgotem a nossa natureza (Wesen). (Heidegger, 1959/2001 p. 24)

Essa é a atitude da serenidade! Talvez uma das veredas a serem trilhadas pelo psicólogo do trabalho e das organizações, na tentativa de resgatar o sentido e o significado da sua atuação profissional, do seu fazer, do seu espaço, do seu lugar.

\section{À guisa de Conclusão}

É chegado o primeiro ponto de parada dessa caminhada rumo à compreensão acerca das questões que inquietam o psicólogo do trabalho e das organizações, no que se refere ao espaço que comumente tem ocupado nas organizações de trabalho. Após termos percorrido esse primeiro trecho, as reflexões trazidas na bagagem carregada ao longo do caminho, articulam-se e sugerem que o lugar, ou melhor, o espaço (Heidegger, 1951/2012) a ser ocupado pelo psicólogo nas organizações de trabalho não esteja exatamente nos níveis operacional, tático ou estratégico, mas entre a técnica e a téchne (Feijoo, 2004). Isto é, enraizado no campo da serenidade (Heidegger, 1959/2001), onde é perfeitamente possível conviver "sem condenar o mundo técnico como uma obra do diabo" (Heidegger, 1959/2001, p. 23). Sem perder de vista o mistério, a imprevisibilidade, a indeterminação do ser, as questões da existência humana, a capacidade de meditar e estar aberto ao mistério, ao mesmo tempo em que também se pode abrir para o pensamento calculante.

Talvez seja esse o espaço que esse psicólogo procura, visto que o lugar da Psicologia do Trabalho e das Organizações - PT\&O já está reconhecido e consolidado, resta ao psicólogo habitá-lo (Heidegger, 1951/2012). Quem sabe um caminho ou vereda esteja entre a técnica e a téchne, exatamente no solo da serenidade onde brotam férteis e harmoniosos os pensamentos calculantes e meditantes. Talvez esse seja o caminho, não o das pedras, não o do campo, mas o das possibilidades para que o psicólogo seja da Psicologia antes de ser do trabalho ou das organizações. Desta forma, quiçá, poderá rever suas práticas, seus saberes, seu espaço, e aí sim, sendo-si-mesmo e sendo-com-os-outros no exercício de sua profissão, não mais se esquecer de ser psicólogo.

\section{Referências}

Associação Brasileira de Psicologia Organizacional e do Trabalho. (2009). Manifesto da Associação Brasileira de Psicologia Organizacional e do Trabalho: psicologia do trabalho e das organizações: não atuamos pela cisão. Brasília. SBPOT. Recuperado de: $<$ http://www.sbpot.org.br/institucional/relatorio-de-gestao/psicologia-organizacional-e-do-trabalho-nao-atuamos-pela-cisao-2009-1.pdf>

Bendassolli, P. F. (2009). Psicologia e Trabalho: apropriações e significados. (Coleção Debates em Administração). São Paulo: Cengage Learning.

Bendassolli, P. F. (2011). Crítica às apropriações psicológicas do trabalho. Psicologia \& Sociedade, 23 (1), 75-84.

Borges, L. O. (2010). A Psicologia do Trabalho e das Organizações no Brasil floresce? Estudos de Psicologia. 15(3), 277-279.

Clot, Y. (2007). A função psicológica do trabalho. (2a ed., A. Sobral, Trad.). Petrópolis, RJ: Vozes. 
Coelho-Lima, F. (2013). A psicologia do trabalho e das organizações na formação do psicólogo no Brasil. (Dissertação de Mestrado). Universidade Federal do Rio Grande do Norte, Natal.

Critelli, D. (2002). Martin Heidegger e a essência da técnica. Margem, 83-89.

Duarte, A. (2004). Heidegger e a possibilidade de uma antropologia existencial. Natureza humana, 6(1), 29-51.

Duarte, A. (2010). Vidas em risco: crítica do presente em Heidegger, Arendt e Foucault. Rio de Janeiro: Forense Universitária.

Dutra, E. (2013). Formação do psicólogo clínico na perspectiva fenomenológico-existencial: dilemas e desafios em tempos de técnicas. Revista da Abordagem Gestáltica, 19(2), 205-211.

Feijoo, A. M. L. C. (2004). A psicologia clínica: técnica e téchne. Psicologia em Estudo, 9(1), 87-93.

Ferreira, I. M. (2005, junho). Bioma cerrado: caracterização do subsistema de vereda. Anais do Encontro Regional de Geografia - Novas territorialidades integração e redefinição regional - EREGEO. Porto Nacional, Goiás, Brasil, 9. Recuperado de https:// observatoriogeogoias.iesa.ufg.br/p/2340-artigos

Gondim, S.M.G.; Bastos. A. V. B., \& Peixoto, L. S. A (2010). Áreas de atuação, atividades e abordagens teóricas do psicólogo brasileiro. Em A. V. B., Bastos, S. M. G, Gondim (Orgs.). O trabalho do psicólogo no Brasil. (pp. 174-199). Porto Alegre: Artmed.

Heidegger, M. (2009). Seminários de Zollikon: protocolos, diálogos, cartas. (M. Boss, Ed., G. Arnhold, \& M. A. Prado, Trads.) Bragança Paulista, SP: Vozes. (Obra original publicada em 1947)

Heidegger, M. (2012). Construir, habitar, pensar. Em M. Heidegger. Ensaios e Conferências. (8a Ed., E. C. Leão. G. Fogel, \& M. S. C. Schuback, Trad.). (Col. Pensamento Humano). Petrópolis/RJ: Vozes; Bragança Paulista: Editora Universitária São Francisco. (Obra original publicada em 1951)

Heidegger, M. (2001). Serenidade. Lisboa: Instituto Piaget. (Obra original publicada em 1959).

Heidegger. M. (2012). Ensaios e Conferências. (8a ed., E. C. Leão. G. Fogel, \& M. S. C. Schuback, Trad.). (Col. Pensamento Humano). Petrópolis/RJ: Vozes; Bragança Paulista: Editora Universitária São Francisco. (Obra original publicada em 1951)

Malvezzi, S. (2014). Prefácio. Em J. C. Zanelli, J. E., Borges-Andrade, \& A. V. B. Bastos (Orgs.), Psicologia, Organizações e Trabalho no Brasil. (2a ed). (pp. ix-xiv). Porto Alegre: Artmed.

Malvezzi, S., Souza, J. A. J., \& Zanelli, J. C. (2010). Inserção no mercado de trabalho: os psicólogos recém-formados. Em A. V. B., Bastos, S. M. G, Gondim (Orgs.). O trabalho do psicólogo no Brasil. (pp. 85-106). Porto Alegre: Artmed.
Santos, M. S. (2007). Integração e diferença em encontros disciplinares. Revista Brasileira de Serviço Social, 22(65), 51-60.

Silva, E. G., \& Barreto, C. (junho de 2015). Uma compreensão do contemporâneo a partir do diálogo com o pensamento de Matin Hiedegger. Griot - Revista de Filosofia, 11(1), 289-299.

Silva, F. L. (2007). Martin Heidegger e a técnica. Scientice Zudia, 5(3), 369-74.

Spink, P. K. (1996) Organização como fenômeno psicossocial: notas para uma redefinição da psicologia do trabalho. Psicologia \& Sociedade,8(1). (jan/jun.) 174-192.

Zanelli, J. C., Bastos, A. V. B., \& Rodrigues, A. C A. (2014). Campo profissional do psicólogo em organizações e no trabalho. Em J. C. Zanelli, J. E., Borges-Andrade, \& A. V. B. Bastos (Orgs.), Psicologia, Organizações e Trabalho no Brasil (2a ed). (pp. 549-582). Porto Alegre: Artmed.

Cynara Carvalho de Abreu é Professora da Universidade Federal do Rio Grande do Norte, Doutora em Educação, Mestre em Administração e Graduada em Psicologia pela Universidade Federal do Rio Grande do Norte. Email: cynara.c.abreu@gmail.com

Symone Fernandes de Melo é Professora da Universidade Federal do Rio Grande do Norte, Mestre em Psicologia Clínica pela Universidade de São Paulo e Doutora em Psicologia pela Universidade Federal de Pernambuco. Email: symelo@gmail.com

Recebido em 23.09.2017 Primeira Decisão Editorial em 17.10.2017 Aceito em 02.05.2018 